Conclusions: Older age, hypoalbuminaemia and renal failure might be poor prognosis factors for low dose MTX-induce myelosuppression in RA.

Disclosure of Interest: None declared

DOI: 10.1136/annrheumdis-2017-eular.3723

\section{THU0202 UNAFFORDABLE CONVENTIONAL AND ABSENT BIOLOGIC DMARDS: INCREASING THE BURDEN OF RHEUMATOID ARTHRITIS IN FYROM}

O. Gjeorgjieva, N. Memeti, L. Damjanovska-Krstikj. University Rheumatology Clinic, University Sts Cyril and Methodius, Skopje, Macedonia, The Former Yugoslav Republic Of

Background: In the developing world rheumatologists and their patients are struggling to implement treat to target therapy in established Rheumatoid Arthritis (RA)which means they can hardly establish remission and low disease activity which is the mainstay of the RA treatment. The main reason is the lack of conventional synthetic and biological (c and b) DMARDs in the therapeutic armamentarium as well as their high cost which increases already difficult burden of RA.

Objectives: The aim of the study is to evaluate the RA treatment and treatment expenses in a group of patients with established RA in FYR of Macedonia including the availability of DMARDs.

Methods: We have conducted a cross-sectional study at the University Rheumatology Clinic in Skopje, including 100 patients with established RA, who fulfilled RA classification criteria from 2010. Physical examination, laboratory analyses and DAS28 were performed and all patients filled a questionnaire with 13 questions about treatment expenses and availability.

Results: There were 82 females and 18 males, with mean age of 59 and disease duration of 8.3 (SD 7,3) years and moderate disease activity DAS28 3,9+/-1,47 and $75 \%$ of seropositive RA (double positive $30 \%$, Ant-CCP positive $30 \%$, RF positive $15 \%$ ) with mean CRP of $21,5 \mathrm{mg} / \mathrm{L}$ They spend from 10 to 100 Euros monthly (on average $27+/-17,6$ ) for the cs DMARDs therapy. Almost $80 \%$ think that the cs DMARDs therapy is too expensive for them and $100 \%$ of them could not afford to pay or co-pay for b DMARDs. Most of the patients (49\%) are using single cs DMARDs. Double and triple c DMARD therapy is used by $32 \%$ vs $17 \%$, respectively. Even though it is highly effective, patients consider triple cs DMARD therapy expensive and with very low compliance because of the high costs and low tolerability. Only $2 \%$ of the patiens are using b DMARDS using rituximab, the only available biologic DMARD therapy in FYROM. Around $70 \%$ are taking low dose prednisolone. Almost $50 \%$ of the patients cannot take the cs DMARD therapy with a prescription and have to buy their DMARDS without any coverage from the insurance fund and the same percent have problems to find the $\mathrm{c}$ DMARDs with prescription because it is not available. Almost half of the patients have heard about the $b$ DMARDs, most of them from their rheumatologist and $54 \%$ of them would like to receive it. The patient's reasons for taking b DMARDs are presented in Graph 1.

Conclusions: High expenses and low availability of c DMARDs on prescription and the urgent need for $b$ DMARDs are adding the burden of RA in developing countries including FYROM with the increased need for full coverage for conventional DMARDs and at least partial coverage of biologic DMARDs, especially anti-TNF agents by the insurance companies. The use of biosimilars might be highly appreciated in the future.

\section{References:}

[1] Aletaha D, Neogi T, Silman AJ et al. 2010 Rheumatoid arthritis classification criteria: An ACR/EULAR collaborative initiative. Arthritis Rheum 2010; 9 (62):2569-2581.

[2] O'Dell JR. Therapies for active rheumatoid arthritis after methotrexate failure N Engl J Med 2013; 369:307-318.

[3] Avci AB, Feist E, Burmester GR. Biologicals in rheumatoid arthritis current and future RMD Open 2015

Disclosure of Interest: None declared

DOI: 10.1136/annrheumdis-2017-eular.6485

\section{THU0203 CHANGES IN C-REACTIVE PROTEIN AND LIPID LEVELS IN PATIENTS WITH RHEUMATOID ARTHRITIS TREATED WITH ABT-494, A SELECTIVE JAK-1 INHIBITOR}

M. Nurmohamed $^{1}$, Y. Zhang ${ }^{2}$, J. Lin ${ }^{2}, \mathrm{H}$. Camp ${ }^{2} .{ }^{1}$ Amsterdam Rheumatology Immunology Ctr, VU Univ Medical Ctr, Amsterdam, Netherlands; ${ }^{2}$ AbbVie, $N$ Chicago, United States

Background: In patients (pts) with rheumatoid arthritis (RA) treated with ABT-494, dose-dependent increases in levels of low and high density lipoprotein cholesterol (LDL-C and HDL-C) were observed, along with decreases in levels of C-reactive Protein (CRP). Whether these changes are due to the control of inflammation or a direct effect on CRP production in the liver is not known.

Objectives: To explore the relationship between changes in HDL-C or LDL-C and CRP with ABT-494 treatment, and to assess whether the effect on lipids is dependent on improvement of RA signs and symptoms.

Methods: Data were from two phase $2 b$ controlled trials of ABT-494 in RA pts with inadequate response or intolerance to TNF inhibitors (TNF-IR, BALANCE-1) ${ }^{1}$, or with inadequate response to methotrexate (MTX-IR, BALANCE-2) ${ }^{2}$. Pts treated

with placebo or 3,6,12,18 mg ABT-494 twice daily for 12 weeks (wks) are included Levels of high sensitivity (hs) CRP, total cholesterol (TC), LDL-C and HDL-C were measured at baseline (BL) and $W k 2,4,6,8$ and 12. Atherogenic burden at $B L$ and Wk 12 was assessed by ratio of ApoB:ApoA1 and TC:HDL-C in 6 mg and 12 $\mathrm{mg}$ dose groups in both studies. Pearson's coefficients were calculated post hoc to assess possible correlations between HDL-C or LDL-C levels (or changes from $\mathrm{BL}$ ) with other variables including (high sensitivity) hsCRP, at BL and Wk 12. Pts were subgrouped by response: Sustained responders (SR), pts who achieved an ACR20 response at every visit from Wk 2-12; Responders (R), pts who achieved ACR20 at least once, but not at every visit; Non-responders (NR), pts who did not achieve ACR20 at any visit.

Results: The ratios of LDL-C:HDL- $\mathrm{C}^{1,2}$ and TC:HDL-C remained unchanged after 12 wks of treatment with ABT-494. The ratio of ApoB:ApoA1 also remained unchanged from BL to Wk 12: in BALANCE-1, 0.61 to 0.58 for the $6 \mathrm{mg}(\mathrm{n}=19)$, and 0.62 to 0.60 for $12 \mathrm{mg}(n=11)$ groups, and in BALANCE-2, 0.62 to 0.64 for the $6 \mathrm{mg}(\mathrm{n}=18)$ and 0.69 to 0.66 for $12 \mathrm{mg}(\mathrm{n}=16)$ groups. An inverse relationship between LDL-C or HDL-C and hsCRP was observed throughout the treatment period. At Wk 4, among the variables tested, the strongest correlation was observed between changes from BL in hsCRP and LDL-C $(-0.29, p<0.001)$ or HDL-C $(-0.26, p<0.001)$. Out of 420 pts, 104 pts $(25 \%)$ were ACR20 SR, 251 pts $(60 \%)$ were R and 65 pts (15\%) were NR. Compared to NR, SR and R had a greater absolute reduction in hsCRP (Fig. 1A). A robust percentage increase in HDL-C was observed in all 3 groups $(20.8 \%, 18.5 \%$ and $16.4 \%$ in SR, R and $N R$, respectively). Compared to the $S R$ and $R(14.6 \%$ and $16 \%$, respectively), a smaller percentage increase in LDL-C was observed in the NR (8.9\%) (Fig. 1B). Figure 1

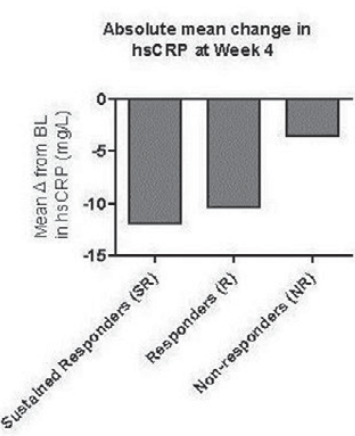

Conclusions: Atherogenic burden did not increase in pts treated with ABT-494 for 12 wks. Compared to non-responders, pts with a clinical response experienced a larger increase in lipids and a larger decrease in hsCRP. Limited data from these phase 2 studies suggest that there might not be an increased risk of cardiovascular events. Results from the larger phase 3 trials can provide more information. References:

[1] Kremer et al. 2016, Arthritis \& Rheum;68:2867

[2] Genovese et al. 2016, Arthritis \& Rheum;68:2857.

Acknowledgements: AbbVie: study sponsor, contributed to study design, data collection, analysis and interpretation; writing, reviewing, and approval of the final version. Medical writing: Naina Barretto, of AbbVie.

Disclosure of Interest: M. Nurmohamed Grant/research support from: Abbvie, Bristol-Myers Squibb, Merck Sharp \& Dohme, Novartis, Pfizer, Roche, Janssen, UCB and Sanofi., Consultant for: Abbvie, Bristol-Myers Squibb, Merck Sharp \& Dohme, Novartis, Pfizer, Roche, Janssen, UCB and Sanofi., Y. Zhang Employee of: AbbVie, J. Lin Employee of: AbbVie, H. Camp Employee of: AbbVie DOI: 10.1136/annrheumdis-2017-eular.2807

\section{THU0204 RELATIONSHIPS BETWEEN METHOTREXATE DOSAGES AND CLINICAL VARIABLES IN PATIENTS WITH RHEUMATOID ARTHRITIS WHO ACHIEVED REMISSION WITH METHOTREXATE MONOTHERAPY: A STUDY USING THE IORRA OBSERVATIONAL COHORT STUDY}

M. Tochihara ${ }^{1}$, Y. Katsumata ${ }^{1}$, E. Inoue ${ }^{1,2}$, Y. Kawaguchi ${ }^{1}$, E. Tanaka ${ }^{1}$, A. Nakajima ${ }^{1}$, K. Ikari ${ }^{1}$, A. Taniguchi ${ }^{1}, \mathrm{H}$. Yamanaka ${ }^{1} .{ }^{1}$ Institute of Rheumatology, Tokyo Women's Medical University; ${ }^{2}$ National Center for Child Health and Development, Tokyo, Japan

Background: Considerable variability exists in the way rheumatologists prescribe methotrexate (MTX) therapy in patients with rheumatoid arthritis (RA), including the dosage [ref.1]. Start higher doses or fast dose escalation are associated with higher efficacy, but also with more toxicity. In addition, factors such as renal function, body size, and age of the patient can affect the optimal dosage of MTX. Objectives: We aimed to study the relationships between MTX dosages and clinical variables in patients with RA who achieved remission with MTX monotherapy. 